\title{
Resident selection for emergency medicine specialty training in Canada: A survey of existing practice with recommendations for programs, applicants, and references
}

\author{
Michael K. P. Hale, MD*; Jason R. Frank, MD, MA(Ed)*+; Warren J. Cheung, MD, MMEd*广
}

\section{CLINICIAN'S CAPSULE}

What is known about the topic?

Little is known about how the Royal College Emergency Medicine (RCEM) residency programs are currently selecting their residents.

What did this study ask?

How are RCEM residency programs currently selecting their residents?

What did this study find?

Heterogeneity exists between programs concerning the value of various selection elements and only 1 of 13 programs has performed a process evaluation.

Why does this study matter to clinicians?

This study characterizes the landscape of RCEM residency selection, improving transparency and acting as a driver for process improvement initiatives.

\section{ABSTRACT}

Objective: Little is known about how the Royal College of Emergency Medicine (RCEM) residency programs are selecting their residents. This creates uncertainty regarding alignment between current selection processes and known best practices. We seek to describe the current selection processes of Canadian RCEM programs.

Methods: An online survey was distributed to all RCEM program directors and assistant directors. The survey instrument included 22 questions and sought both qualitative and quantitative data from the following six domains: application file, letters of reference, elective selection, interview, rank order, and selection process evaluation.

Results: We received responses from 13 of 14 programs for an aggregate response rate of $92.9 \%$. A candidate's letters of reference were identified as the most important criterion from the paper application (38.5\%). Having a high level of familiarity with the applicant was the most important characteristic of a reference letter author (46.2\%). In determining rank order, $53.8 \%$ of programs weighed the interview more heavily than the paper application. Once final candidate scores are established following the interview stage, all program respondents indicated that further adjustment is made to the final rank order list. Only 1 of 13 program respondents reported ever having completed a formal evaluation of their selection process.

Conclusion: We have identified elements of the selection process that will inform recommendations for programs, students, and referees. We encourage programs to conduct regular reviews of their selection process going forward to be in alignment with best practices.

\section{RÉSUMÉ}

Introduction: On ne sait pas vraiment comment se fait la sélection des candidats aux programmes de résidence en médecine d'urgence du Collège royal (MUCR), ce qui ajoute de l'incertitude quant à I'harmonisation des processus courants de sélection avec les pratiques exemplaires connues. L'étude visait donc à faire état des processus de sélection des candidats en vigueur dans les programmes de résidence en MUCR.

Méthode: Un questionnaire d'enquête en ligne a été envoyé à tous les directeurs et directeurs adjoints des programmes de MUCR. L'instrument comptait 22 questions et visait à recueillir des données tant qualitatives que quantitatives sur les six domaines suivants : les dossiers de demande, les lettres de recommandation, le choix des stages facultatifs, les entrevues, le classement par ordre de rang et l'évaluation des processus de sélection.

Résultats: L'équipe a reçu les questionnaires remplis de 13 programmes sur 14, soit un taux global de réponse de $92,9 \%$. Les lettres de recommandation se sont révélées l'élément le plus important du dossier de demande (38,5\%).

From the ${ }^{*}$ Department of Emergency Medicine, University of Ottawa, Ottawa, ON; and the ${ }^{\dagger}$ Ottawa Hospital Research Institute, Ottawa, ON.

Correspondence to: Dr. Warren Cheung, Clinical Epidemiology Unit, F660, The Ottawa Hospital, 1053 Carling Avenue, Ottawa, ON K1Y 4E9; Email: wcheung@toh.on.ca. 
Le fait de bien connaître les candidats était le facteur le plus important des auteurs des lettres de recommandation $(46,2 \%)$. Quant au classement des candidats, les entrevues avaient plus d'importance que le dossier de demande luimême dans $53,8 \%$ des programmes. Par ailleurs, selon les répondants, une fois calculés les résultats finaux des candidats après les entrevues, des adaptations étaient apportées, dans tous les programmes, à la liste définitive du classement par ordre de rang. Enfin, dans un seul programme sur treize, les responsables ont indiqué avoir déjà procédé à une évaluation structurée des processus de sélection.
Conclusion: L'étude a permis de dégager certains éléments du processus de sélection qui orienteront les recommandations concernant les responsables de programme, les étudiants ainsi que les auteurs des lettres de recommandation. En outre, les équipes de direction des programmes sont invitées à examiner régulièrement, à l'avenir, leurs processus de sélection afin de les harmoniser avec les pratiques exemplaires en la matière.

Keywords: Emergency medicine, residency, selection

\section{INTRODUCTION}

In Canada, emergency medicine consistently ranks among the most competitive residency specialties with only 0.58 positions available per applicant. ${ }^{1,2}$ Unfortunately, little is known about how Royal College Emergency Medicine (RCEM) residency programs are currently selecting their residents. In general, the process of selection is complex, relying on a series of imperfect criteria without an established gold standard..$^{3-5}$ Amid talented applicant pools where differences between candidates are often subtle, the process of selection can pose an even greater challenge.

In the United States, there have been multiple studies that have helped identify the most important application elements in the U.S. residency match. ${ }^{1,6-8}$ Across these studies, objective criteria, including clerkship grades and United States Medical Licensing Examination (USMLE) scores, were consistently considered to be important factors. In Canada, we do not have a standardized test, such as the USMLE, to act as a benchmark for student aptitude. Our medical school grading system is "pass" or "fail" at a majority of schools. ${ }^{9}$ As such, students and selection committees alike have relatively fewer objective data points to consider. Which criteria Canadian residency programs are relying on remain unclear, creating the potential for an incongruent process both within and across specialties. ${ }^{10}$ Moreover, medical students often identify that they find the selection process to be ambiguous and too heavily reliant on subjective criteria. ${ }^{11}$ Before improvements can be made, however, our current selection practices must first be adequately characterized. To our knowledge, no other study has sought to achieve this characterization at a national level.
The objective of our study is to develop a better understanding of the Canadian residency selection process in emergency medicine through the use of a national program director survey. Specifically, we aim to identify which elements of the Canadian Residency Matching Service $(\mathrm{CaRMS})^{12}$ application are most valued by program directors. This will add transparency to the selection process for future candidates and provide valuable information to selection committees who will be able to evaluate how their selection practices differ from those of other Canadian programs and established best practice guidelines. ${ }^{13,14}$ Information gained will fill a void in the Canadian residency selection literature and act as an important driver for future process improvement initiatives.

\section{METHODS}

\section{Study design}

An online survey was distributed to all Royal College of Physicians and Surgeons of Canada emergency medicine programs via email using the modified Dillman's Tailored Design Method. ${ }^{15}$ The initial email contained information about the purpose and goals of the study, as well as the survey link. The survey was hosted on the SurveyMonkey Team Advantage platform. Up to three reminder emails were sent, each spaced by a two-week time interval. Research was conducted between March and May of 2019. An ethics waiver was obtained from the Ottawa Health Science Network Research Ethics Board.

\section{Population}

Surveys were distributed to program directors and assistant program directors from all 14 Canadian RCEM 
programs. Our goal was to receive a response from each program to ensure a balanced national perspective. If both the program director and the assistant program directors from a single program submitted a survey, only the program director survey was used for data analysis.

\section{Survey design}

The survey content was developed by the study authors (one resident and two clinician educators) ${ }^{16}$ in consultation with three members of the residency selection committee of the University of Ottawa, Department of Emergency Medicine. Important elements of the application file, interview, and ranking process were identified and ultimately used to develop the questions for our survey. Text boxes for narrative comments were provided to allow respondents to elaborate or qualify their responses. The preliminary survey was piloted on the Canadian College of Family Physicians Emergency Medicine (CCFP-EM) certificate program directors at the University of Ottawa for clarity and comprehensibility, and further refinements to the survey were made based on pilot feedback. In its final version, our survey consisted of 22 items containing both open and closed-ended elements (Appendix A). Questions addressed the following six domains: application file, letters of reference, elective selection, interview, rank order, and selection process evaluation. The importance of each element was measured using a five-point Likert scale $(1=$ not at all important, 5 = very important).

\section{Data analysis}

Simple descriptive statistics were used to report the survey results. Percentages, means, and standard deviations were calculated for Likert scale responses; percentages were calculated for questions requiring the selection of a single drop-down answer choice. Data analysis was conducted using Microsoft Excel for Mac version 16.34. Openended questions were categorized into themes by the study authors if two or more respondents answered similarly. Only responses that could be categorized into themes were included in the results section. Narrative responses that clarified a closed-ended question were not mandatory fields and therefore do not necessarily reflect consensus opinion. Because of this, these data were not included in the results section and only used in the discussion if they were felt to enrich the dialogue.

\section{RESULTS}

In total, 13 of 14 Canadian RCEM residency programs completed our survey for an aggregate response rate of $92.9 \%$. Program directors accounted for $76.9 \%$ of responses with the remainder from assistant program directors.

Table 1 displays the relative importance of each of the elements of the CaRMS application file. Letters of reference, curriculum vitae (CV), and the personal letter were identified as the three most important elements. Of these, letters of reference were most frequently identified as the most important. Respondents did not feel strongly that a candidate's research experience had to be specifically in the field of emergency medicine.

Table 2 displays the relative importance of different characteristics of letter of reference authors. Having a high level of familiarity with the applicant, specializing in emergency medicine, and having an academic centrebased practice were the three most important characteristics; of these, having a high level of familiarity with the applicant was most frequently identified as the most important. The author being well known in the emergency medicine community was considered significantly less important by respondents. If an applicant completed an elective at their institution, $38 \%$ of respondents indicated that a letter written by a faculty member of their own program was important or very important.

The majority of respondents $(76.9 \%)$ indicated that spending 26-75\% of CaRMS elective time in emergency medicine demonstrated commitment to the specialty. Only a single respondent indicated that completing an elective at their institution was important or very important, and all respondents stated that a candidate could be invited for an interview if they did not do an elective at their institution.

\begin{tabular}{|c|c|}
\hline Application file elements & $\begin{array}{l}\text { Rated as single most } \\
\text { important element (\%) }\end{array}$ \\
\hline Letters of reference & 38.5 \\
\hline Curriculum vitae & 30.8 \\
\hline Transcript & 15.4 \\
\hline Personal letter & 7.7 \\
\hline Other & 7.7 \\
\hline Research experience & 0.0 \\
\hline Dean's letter (MSPR) & 0.0 \\
\hline
\end{tabular}




\begin{tabular}{|c|c|}
\hline Preceptor characteristics & $\begin{array}{c}\text { Rated as single most important } \\
\text { characteristic (\%) }\end{array}$ \\
\hline $\begin{array}{l}\text { Writer has a high level of } \\
\text { familiarity with the applicant }\end{array}$ & 46.2 \\
\hline $\begin{array}{l}\text { Writer specializes in emergency } \\
\text { medicine }\end{array}$ & 30.8 \\
\hline $\begin{array}{l}\text { Writer has an academic } \\
\text { centre-based practice }\end{array}$ & 7.7 \\
\hline You personally know the writer & 7.7 \\
\hline Other & 7.7 \\
\hline $\begin{array}{l}\text { Writer has been in clinical practice } \\
\text { for } 5 \text { years or more }\end{array}$ & 0.0 \\
\hline $\begin{array}{l}\text { Writer is well known in the EM } \\
\text { community }\end{array}$ & 0.0 \\
\hline Writer is an FRCPC graduate & 0.0 \\
\hline
\end{tabular}

When the interview stage is reached, $76.9 \%$ of respondents stated that the interview was weighted at least as much as the paper application in determining final rank order. Over half, $53.8 \%$, stated that the interview was weighted more heavily; $76.9 \%$ of programs conducted structured interviews, where each candidate is asked the same set of questions in the same order; and less than half of these programs used a standardized rubric to evaluate candidates' interview responses.

Table 3 demonstrates the relative importance of select interviewee qualities. Demonstrating honesty and sincerity with answers, providing clear and articulate answers, and offering unique or refreshing answers were identified as the three most important interview elements. Of these, demonstrating honesty and sincerity with answers was rated as the most important by the majority of respondents $(61.5 \%)$.

When final candidate scores are established for both the paper application and the interview, $100 \%$ of program respondents acknowledged that further adjustment is made to the rank order list before final submission. All program respondents agreed that a candidate's perceived program ranking did not affect their ranking of the candidate.

When asked what the single most important thing that a prospective candidate could do to improve their chances of matching to an emergency medicine residency program, respondents varied greatly in their responses. Being strong clinically $(23.1 \%)$ and demonstrating interest in a particular program $(15.4 \%)$ were the most cited themes.

\begin{tabular}{|c|c|}
\hline Interviewee qualities & $\begin{array}{l}\text { Rated as single most } \\
\text { important characteristic (\%) }\end{array}$ \\
\hline $\begin{array}{l}\text { Candidate demonstrates honesty } \\
\text { and sincerity with answers }\end{array}$ & 61.5 \\
\hline $\begin{array}{l}\text { Candidate provides clear and } \\
\text { articulate answers }\end{array}$ & 23.1 \\
\hline $\begin{array}{l}\text { Candidate offers a unique/ } \\
\text { refreshing answer to a question }\end{array}$ & 7.7 \\
\hline Other & 7.7 \\
\hline $\begin{array}{l}\text { Candidate demonstrates having } \\
\text { prepared responses to common } \\
\text { questions }\end{array}$ & 0.0 \\
\hline Candidate gets the answer "right" & 0.0 \\
\hline $\begin{array}{l}\text { Candidate states that your program } \\
\text { is their first choice }\end{array}$ & 0.0 \\
\hline Candidate is memorable & 0.0 \\
\hline
\end{tabular}

The majority (69.2\%) of respondents indicated that their strongest residents were "often" or "almost always" the highest-ranked candidates in their respective CaRMS application year. Only one of the programs (7.7\%) reported ever having completed a formal evaluation of their CaRMS selection process to determine effectiveness.

For an in-depth question by question breakdown of quantitative responses, please refer to Appendix A. For a snapshot of key takeaways for programs, students, and references, refer to Table 4.

\section{DISCUSSION}

\section{Interpretation of results}

The information gained from this study helps characterize the landscape of the RCEM residency selection process. We identified significant heterogeneity between programs concerning the importance of various elements of the application file where standard deviations approached and often exceeded one point (five-point Likert scale). Although generally being considered of low importance overall, transcripts and dean's letters demonstrated notably high variability, suggesting that they should not be entirely neglected. The understanding of a program director regarding the relationship between the CaRMS ranking of their residents and future performance was also highly variable and possibly 
Table 4. Key takeaways for programs, students, and references

Program takeaways

1 Medical student schedules should be designed to allow multiple shifts with the same preceptor.

2 Internal selection criteria and processes should be standardized and explicitly stated. ${ }^{13}$

3 Process reviews and outcome evaluations should be conducted regularly. ${ }^{13}$

Student takeaways

1 Request letters of reference from EM physicians who know you well, rather than seeking a "big name" in emergency medicine.

2 Aim to spend the maximum allowable CaRMS elective time in emergency medicine to demonstrate commitment to the specialty.

Reference takeaways

1 Outline how often you work with students during your introduction.

2 Provide a relative ranking of the student compared to other students you have worked with.

3 Avoid reusing letters or ranking all students in the same high percentile.

relates to an overall lack of regular process/outcome evaluation. Recent calls for regular assessment of process outcomes have been published in Best Practices in Application and Selection (BPAS) for residency programs in Canada. ${ }^{13,14}$ However, in our study, only 1 of 13 programs had ever performed a formal evaluation of their selection process. As such, outcomes evaluation of Canadian emergency medicine selection processes represents a much needed area of future study. The ultimate goal of selection should be to effectively identify the candidates who most wholly possess the characteristics that a given program desires. These characteristics may vary somewhat between programs but should be made explicit and the processes used to select them internally standardized. ${ }^{13}$

Letters of reference emerged as the most important element of a candidate's application file. Our data would suggest that applicants can improve the perceived quality of their reference letters by performing electives at academic hospitals and by asking for reference letters from emergency medicine preceptors who know them well, rather than targeting a well-known name in the emergency medicine community. The commonly held belief that the "name" of the writer matters above all else has been discredited. Programs can assist candidates with achieving improved familiarity by scheduling students with the same preceptor over multiple shifts. For preceptors, indicating how many students/residents they typically work with and providing a ranking relative to other trainees were helpful for several respondents. Certain respondents also felt that frequently reusing the same letters or ranking multiple applicants in the same high percentile detracted from the quality of a letter.

There is a growing body of evidence suggesting that non-structured or "narrative" letters of reference are highly subjective, inconsistent for the range of qualities described, and demonstrate suboptimal inter-rater agreement among readers. ${ }^{17,18}$ Including a relative ranking of a candidate, as suggested previously, could help facilitate comparisons between applicants and improve alignment with the BPAS recommendation of striving to incorporate more objective assessment strategies. ${ }^{13}$ A potentially more robust solution could be to transition to standardized letters of reference (SLOR). SLORs consist of a set of standardized domains that can be tailored to a given specialty's unique features. ${ }^{17}$ In general, SLORs have been shown to allow for more direct comparisons between candidates and improved inter-rater reliability, ${ }^{17-19}$ likely improving the overall utility of the letter of reference as a selection instrument.

Consistent with other studies, research experience ranked lower among selection criteria with only $38.5 \%$ of respondents identifying it to be important or very important ${ }^{1,6,8}$; what is clear from other studies is that perceived commitment to a specialty is a factor often considered by selections committees, ${ }^{6,19}$ and research is one possible way to demonstrate this. Another is through elective choice. In our study, spending anywhere from $26-75 \%$ of CaRMS elective time in emergency medicine demonstrated commitment to the specialty. However, the Association of Faculties of Medicine of Canada has recently enacted a policy, effective beginning with the Class of 2021, that restricts student electives to a maximum of eight weeks in any single entry-level discipline, such as emergency medicine. ${ }^{20}$ Therefore, we recommend that students spend the maximum allowable CaRMS elective time in emergency medicine to demonstrate commitment to the specialty.

The majority of respondents reported that the interview is weighted more heavily than the application file in determining final rank order, consistent with much of the residency selection literature. ${ }^{6,8}$ Structured interviews where each candidate is asked the same questions 
in the same order were used in $76.9 \%$ of programs. Less than half $(46.2 \%)$ use a standardized framework to evaluate responses. This raises some concerns about the reliability of the interview process. Although there is no definitive interview format that is considered to be the gold standard, it is generally well accepted that unstructured interviews are highly subjective and demonstrate low reliability. ${ }^{4,21-23}$ On the other hand, evidence for the validity and relative reliability of structured interviews has been previously shown. ${ }^{4,24}$ One study demonstrated that implementing a half-day course that teaches the fundamentals of structured interviewing can substantially improve interviewer knowledge and inter-rater agreement, even among experienced interviewers. ${ }^{23}$ Despite this, the literature continues to demonstrate a poor association between the interview and future resident performance. ${ }^{21,22}$ Additional research is needed to better understand what interview factors (e.g., format, content, method) are most helpful in identifying candidates who will later become successful residents.

\section{Strengths and limitations}

To the best of our knowledge, our study is the first to perform a comprehensive analysis of the Canadian RCEM residency selection process. The $92.9 \%$ response rate is a notable strength and helps ensure a balanced national perspective. The retrospective nature of the study is one potential limitation as certain aspects of our data will be subject to recall bias. Another limitation is that data collection using a survey instrument is inherently subject to a degree of self-report and social desirability bias. Having focused exclusively on Canadian emergency medicine residency programs, our results may not be generalizable to other specialties or geographic regions. Finally, as we focused exclusively on program directors and assistant program directors, our data may differ somewhat from the opinions of other selection committee members.

\section{Study implications and future directions}

The information gained from this study has characterized the landscape of the Canadian residency selection process in emergency medicine. It immediately adds transparency to the process for prospective candidates allowing for increased confidence when deciding where to focus their attention. For selection committees, the data provide an easy way to identify where their practice differs from other Canadian programs/selection best practices. ${ }^{14,25}$ Now that we have a firm understanding of what factors are currently driving selection decisions, this study sets the stage for future research that aims to identify selection methods that are more predictive of future resident performance. With the transition to competency-based medical education and the resultant shift to more comprehensive resident assessments, the current climate is timely to conduct such research.

\section{CONCLUSION}

We have identified the most important elements of the residency application in emergency medicine: letters of reference, $\mathrm{CV}$, and interview performance. Medical students should target letters of reference from preceptors who know them well, programs should provide opportunities for students to experience multiple shifts with the same preceptors, and referees should provide context regarding how a student compares to others. Going forward, residency programs are encouraged to conduct regular reviews of their selection process to ensure internal consistency and fairness to applicants.

Supplemental material: To view supplementary material for this article, please visit https://doi.org/10.1017/cem.2020.457.

\section{REFERENCES}

1. Green M, Jones P, Thomas JX. Selection criteria for residency: results of a national program directors survey. Acad Med 2009;84(3):362-7.

2. The Canadian Resident Matching Service (CaRMS). CaRMS forum; 2019. Available at: https://www.carms.ca/pdfs/2019CaRMS-Forum-data.pdf (accessed February 6, 2020).

3. Van Meter M, Williams M, Banuelos R, Carlson P. Does the national resident match program rank list predict success in emergency medicine residency programs? 7 Emerg Med 2017;52(1):77-82.e1, doi:10.1016/j.jemermed.2016.06.059.

4. Prideaux D, Roberts C, Eva K, et al.. Assessment for selection for the health care professions and specialty training: consensus statement and recommendations from the Ottawa 2010 Conference. Med Teach. 2011;33:215-23, doi:10.3109/ 0142159X.2011.551560.

5. Bandiera G, Abrahams C, Ruetalo $M$, et al.. Identifying and promoting best practices in residency application and selection in a complex academic health network. Acad Med 2015;90 (12):1594-601, doi:10.1097/ACM.0000000000000954.

6. Crane J, Ferraro C. Selection criteria for emergency medicine residency applicants. Acad Emerg Med 2000;7(1):54-60. 
7. Katzung KG, Ankel F, Clark M, et al.. What do program directors look for in an applicant? 7 Emerg Med 2019;56(5): e95-e101, doi:10.1016/j.jemermed.2019.01.010.

8. Negaard M, Assimacopoulos E, Harland K, Van Heukelom J. Emergency medicine residency selection criteria: an update and comparison. AEM Educ Train 2018;2(2):146-53, doi:10.1002/aet2.10089.

9. Glauser W. Quebec medical schools slow to adopt pass/fail system. CMA7 2017;189(48):1499-500, doi:10.1503/ cmaj.109-5525.

10. Wycliffe-Jones K, Hecker KG, Schipper S, et al. Selection for family medicine residency training in Canada. Can Fam Pbysician 2018;64:129-34.

11. Ryan T. Addressing bias and lack of objectivity in the Canadian resident matching process. CMAJ 2018;190(40):1211-2, doi:10.1503/cmaj.70008.

12. CaRMS. 2020 Main Residency Match; 2020. Available at: https://www.carms.ca/match/r-1-main-residency-match (accessed February 6, 2020).

13. Bandiera G, Abrahams C, Cipolla A, et al. Best practices in applications \& selection, final report; 2013. Available at: https://pg.postmd.utoronto.ca/wp-content/uploads/2016/06/ BPASDraftFinalReportPGMEACMay2013.pdf (accessed February 2, 2020).

14. Roger A, Epstein I, Bandiera G. Applying best practices in application and selection (BPAS) in your residency program. In: The International Conference on Residency Education. Halifax: Nova Scotia; 2018.

15. Dillman DA. Mail and Internet surveys: the Tailored Design Method. 2nd ed. New York: Wiley; 2000.

16. Sherbino J, Frank JR, Snell L. Defining the key roles and competencies of the clinician-educator of the 21 st century: a national mixed-methods study. Acad Med 2014;89(5):783-9, doi:10.1097/ACM.0000000000000217.

17. Langdorf MI, Cheaito MA, Epter M, Kazzi A. Letters of recommendation. $f$ Emerg Med 2020;57(3):405-10, doi:10.1016/j.jemermed.2019.04.020.

18. Fortune JB. The content and value of letters of recommendation in the resident candidate evaluative process. Curr Surg 2002;59(1):79-83.

19. Hartman ND, Lefebvre CW, Manthey DE. A narrative review of the evidence supporting factors used by residency program directors to select applicants for interviews. $7 \mathrm{Grad}$ Med Educ 2019;11(3):268-73.

20. AFMC. Elective diversification; 2020. Available at: https:// afmc.ca/en/priorities/elective-diversification (accessed June 5, 2020).

21. Stephenson-Famy A, Houmard BS, Manyak A. Use of the interview in resident candidate selection: a review of the literature. 7 Grad Med Educ 2015;7(4):539-48.

22. Kenny S, Mcinnes M, Singh V. Associations between residency selection strategies and doctor performance: a meta-analysis. Med Educ 2013;47(8):790-800, doi:10.1111/medu.12234.

23. Gardner AK, Onofrio BCD, Dunkin BJ. Can we get faculty interviewers on the same page? An examination of a structured interview course for surgeons. 7 Surg Educ 2018;75 (1):72-7.\{print update\}

24. Blouin D, Day A, Pavlov A. Comparative reliability of structured versus unstructured interviews in the admission process of a residency program. 7 Grad Med Educ 2011;3(4):517-23.

25. Paterson QS, Hartmann R, Woods R, Martin LJ, Thoma B. A transparent and defensible process for applicant selection within a Canadian emergency medicine residency program. CFEM 2020;22(2):215-23. 